\title{
Complete Vagotomy and its Consequences: Follow-up of 146 Patients
}

\author{
C. G. CLARK,* M.D., F.R.C.S., F.R.C.S.ED.; J. G. MURRAY, † CH.M., F.R.C.S.ED.; I. M. SLESSOR, $\ddagger$ M.B., CH.B.; \\ J. H. WYLLIE,§ B.SC., M.D.
}

Brit. med. F., 1964, 2, 900-903

Division of all vagal branches to the stomach may be important in the treatment of duodenal ulcer. As long ago as 1947 Dragstedt and his colleagues pointed out that if a branch of the vagus is inadvertently missed at operation there may be reactivation of the whole of the glandular apparatus, return of high acid secretion, and consequent recurrence of ulceration; more recently Murray (1962a) discussed the mechanism of return of nervous activity. In 1958 Burge and Vane introduced a method of testing for completeness of vagal section at the time of operation, and Clark and Murray (1963) investigated the usefulness of the test in 100 patients. This report is concerned with a follow-up from two to five years after operation in which "complete vagotomy" was carried out. In all cases the drainage procedure was gastro-enterostomy.

An attempt has been made to answer a number of questions. Does complete vagotomy confer an immunity from recurrence of ulceration? How does morbidity after complete vagotomy compare with that after incomplete nerve section and after partial gastrectomy?

A question of a different kind is whether it is possible to select the appropriate surgical treatment for an individual patient on the basis of pre-operative gastric secretory studies. Bruce et al. (1959), Gillespie and Kay (1961), and Orr (1963) believe that the augmented histamine test is useful in indicating which patients are best treated by vagotomy. The results in the series have been studied to see if there is support for this view.

\section{Methods}

Vagotomy and gastro-enterostomy was adopted by us in 1958 as the method of treatment for all patients with uncomplicated duodenal ulcer requiring surgery. A number of patients had already been submitted to operation before we began investigating the test described by Burge and Vane (1958). When the test was introduced we elected to apply it in two cases of every three, allotting the third case to a control group. The stimulation tests have been described fully elsewhere (Clark and Murray, 1963). Of the 100 patients undergoing the test seven proved unsuitable, either because the response to electrical stimulation before dividing the nerves was too small or because premedication with atropine or pethidine had been given. These seven patients were allocated to the control group. After vagotomy a gastro-enterostomy was fashioned. Initially, alternate antecolic and retrocolic gastro-enterostomies were performed, but after 26 antecolic procedures had been carried out this method was abandoned and the remainder were retrocolic isoperistaltic, with a short afferent loop at the most dependent part of the stomach.

In 132 patients a pre-operative augmented histamine test was carried out using the technique described by Kay (1953). The acid secreted in one hour after histamine was measured and expressed in milliequivalents; this was the most accurate method for comparison of secretory rates in different patients

\footnotetext{
- Senior Lecturer in Surgery, University of Aberdeen.

t Reader in Surgery, King's College Hospital, London.

$\ddagger$ Reader in Surgery, King's College Hospital

S Surgical Registrar, Aberdeen Royal Infirmary.
}

(Clark et al., 1964b). Post-operative histamine tests were carried out on a number of patients at varying intervals after operation and in all cases of suspected recurrent ulcer. In addition, insulin tests (Hollander, 1946) were performed. Recurrent ulcers were diagnosed by barium meal or gastroscopy, and were confirmed at operation in five of the six cases.

The patients were seen at regular intervals, and at each attendance questions were asked from a prescribed form. In addition to questions on general health, specific attention was paid to the presence or absence of alimentary symptoms. Prior to operation a record was made of the patient's normal bowel habit, and at review any change in bowel habit was ascertained. A record of the patient's weight and haemoglobin was kept. The results have, for simplicity, been classified as follows:

1. Excellent.-These patients are completely free from ulcer symptoms, and have no post-operative alimentary disturbance.

2. Good.-These patients are free from ulcer symptoms, and enjoy good health; but they have some intermittent post-operative symptoms such as bilious vomiting, diarrhoea, or dumping, which detract from complete satisfaction with the operation.

3. Poor.-These patients have post-operative symptoms which impair health or ability to work or take part in social activities. The symptoms are often as disturbing to the patient as the original ulcer.

4. Failed.-Proved recurrent ulcer.

The problems in assessing any operative procedure for the treatment of duodenal ulcer have been discussed by Tanner (1964). Highly controversial figures are given for the results and frequency of side-effects of the same operation carried out in a similar way and with comparable dexterity by different surgeons. It is clear that different standards are used, and there is a difference in assiduity with which the patients are questioned. To overcome some of these difficulties, one surgeon (C. G. C.) carried out the follow-up in this series and in a gastrectomy series (Clark and Logie, 1962), using the standard set of questions. The two groups were operated upon in the same hospital (Aberdeen Royal Infirmary) and came from the same community. The gastrectomy series (Clark and Logie, 1962) preceded in time the vagotomy group. When surgery was thought necessary no form of selection was employed-in the first series Polya partial gastrectomy was used exclusively, and in the second vagotomy and gastro-enterostomy.

\section{Results}

Table I shows a comparison of the two groups of patients treated by vagotomy, with and without electrical stimulation tests. The group subjected to stimulation tests is larger than the control group because of the method of selection. All cases could not be followed up. One patient in the test group died after operation as a result of pulmonary embolism, and another has since died of a bronchial carcinoma. Three patients could not be traced, and of the remaining 88 , four have left the region and would not be interviewed but did reply to a detailed questionary. In the control group two patients have died since operation-one of a cerebral vascular accident and the other as a result of trauma. Five patients could not be traced. Of the remaining 58, 55 were seen personally, and the remaining, three completed the questionary. 
The two groups are comparable in age, sex, average duration of symptoms pre-operatively, and incidence of pre-operative complications. The distribution of acid secretion encountered in the two groups is also similar.

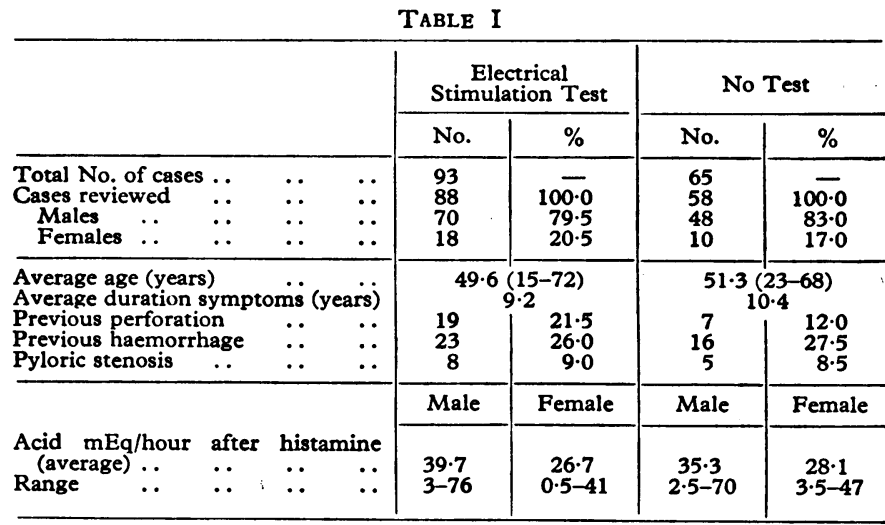

Table II shows the overall results in the two groups who have undergone vagotomy. There is no significant difference between those who had been subjected to stimulation tests and those who had not. About $86 \%$ of the results were satisfactory (excellent and good) and about $14 \%$ were unsatisfactory (poor and failed). The 26 patients with antecolic gastro-enterostomies are equally distributed between the tested and untested groups.

\begin{tabular}{|c|c|c|c|c|c|c|c|c|c|c|}
\hline \multirow{3}{*}{\multicolumn{2}{|c|}{ Result }} & & \multicolumn{6}{|c|}{$\begin{array}{c}146 \text { Cases } \\
\text { Vagotomy and Gastro-enterostomy } \\
(2-5 \text { years })\end{array}$} & \multirow{2}{*}{\multicolumn{2}{|c|}{$\begin{array}{c}331 \text { Cases } \\
\text { Partial } \\
\text { Gastrectomy } \\
\text { (5-15 } \\
\text { Years) } \\
\end{array}$}} \\
\hline & & & \multicolumn{2}{|c|}{ Test } & \multicolumn{2}{|c|}{ No Test } & \multicolumn{2}{|c|}{ Combined } & & \\
\hline & & & No. & $\%$ & No. & $\%$ & No. & $\%$ & No. & $\%$ \\
\hline $\begin{array}{l}\text { Excellent } \\
\text { Good ... } \\
\text { Poor . } \\
\text { Failed }\end{array}$ & 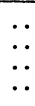 & $\begin{array}{l}\ddot{0} \\
\ddot{x}\end{array}$ & $\begin{array}{r}53 \\
23 \\
9 \\
3\end{array}$ & $\begin{array}{r}60 \cdot 0 \\
26 \cdot 0 \\
10 \cdot 0 \\
3 \cdot 5\end{array}$ & $\begin{array}{r}40 \\
10 \\
5 \\
3\end{array}$ & $\begin{array}{r}70 \\
17 \\
8 \\
5\end{array}$ & $\begin{array}{r}93 \\
33 \\
14 \\
6\end{array}$ & $\begin{array}{r}63 \cdot 5 \\
23 \cdot 0 \\
9 \cdot 5 \\
4 \cdot 0\end{array}$ & $\begin{array}{r}203 \\
87 \\
24 \\
17\end{array}$ & $\begin{array}{r}61 \cdot 3 \\
26 \cdot 3 \\
7 \cdot 3 \\
5 \cdot 1\end{array}$ \\
\hline
\end{tabular}

Table III shows the results of antecolic and retrocolic anastomosis; the antecolic procedure was abandoned because gastric drainage in the immediate post-operative period was much more troublesome than after the retrocolic type. There are fewer excellent results with antecolic gastro-enterostomy and a higher proportion of recurrent ulcers. It is stressed, however, that the numbers are small.

\begin{tabular}{|c|c|c|c|c|c|}
\hline & & \multicolumn{4}{|c|}{ Vagotomy } \\
\hline & & \multicolumn{2}{|c|}{ Antecolic Gastro-enterostomy } & \multicolumn{2}{|c|}{ Retrocolic Gastro-enterostomy } \\
\hline & & No. & $\%$ & No. & $\%$ \\
\hline $\begin{array}{l}\text { Excellent } \\
\text { Good .. } \\
\text { Poor .. } \\
\text { Failed.. }\end{array}$ & $\begin{array}{l}\because \\
\because \\
\end{array}$ & $\begin{array}{r}13 \\
6 \\
4 \\
3\end{array}$ & $\begin{array}{l}50 \\
23 \\
15 \\
12\end{array}$ & $\begin{array}{l}80 \\
27 \\
10 \\
3\end{array}$ & $\begin{array}{r}67.0 \\
22.5 \\
8 \cdot 0 \\
2 \cdot 5\end{array}$ \\
\hline
\end{tabular}

Table IV shows the incidence of commoner side-effects after vagotomy and gastro-enterostomy. Many of these were of a minor nature and in no way interfered with health, work or social activities. In addition, 26 patients suffered from dysphagia. This was a temporary phenomenon except in one

TABLE IV

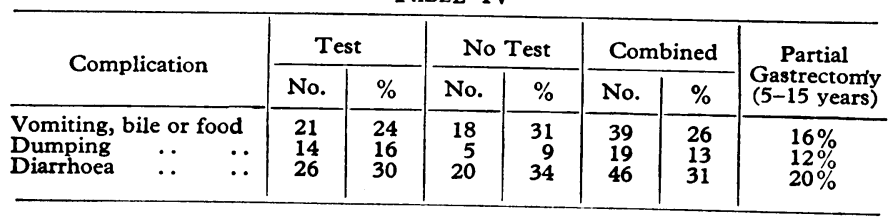

patient who was subsequently shown to have a hiatus hernia. The dysphagia disappeared when the hernia was repaired.

Bilious vomiting occurred with about equal frequency in the two vagotomy groups. In a number of patients it occurred two or three times a year without being a major problem. Often they were aware for a few hours or a day that it was about to take place. Not uncommonly they also suffered from intermittent diarrhoea preceded by mild epigastric discomfort. The patient, while being aware that something was going to happen, was often uncertain at which end of the alimentary tract it might present. In only seven instances was bilious vomiting a serious feature (Table V); nevertheless this represents half of the " poor" results.

\section{TABLE V.-Poor Results}

\begin{tabular}{|c|c|c|}
\hline Case No. & Complications & Present Status \\
\hline T.1 & $\begin{array}{l}\text { Hiatus hernia } \\
\text { Bilious vomit and severe } \\
\text { diarrhoea. }\end{array}$ & $\begin{array}{l}\text { Satisfactory after hernia repair } \\
\text { Satisfactory after conversion to pyloro- } \\
\text { plasty }\end{array}$ \\
\hline T.18 & Bilious vomit & Satisfactory after excision of omental \\
\hline T.27 & Bilious vomit and dumping & Unchanged \\
\hline $\begin{array}{l}\mathrm{T} .32 \\
\mathrm{~T} .38 \\
\mathrm{TF} .6\end{array}$ & $\begin{array}{l}\text { Diarrhoea } \\
\text { Bilious vomit and diarrhoea }\end{array}$ & $\begin{array}{l}\text { Improved on pancreatic extract } \\
\text { Unchanged }\end{array}$ \\
\hline $\begin{array}{l}\text { TF.8 } \\
\text { TF.15 } \\
\text { NT.2 }\end{array}$ & $\begin{array}{l}\text { Vomiting food, weight loss } \\
\text { Diarrhoea intestinal ob- }\end{array}$ & $\begin{array}{l}\text { Improved on pancreatic extract } \\
\text { Improved after Noble plication }\end{array}$ \\
\hline $\begin{array}{l}\text { NT.14 } \\
\text { NT.17 } \\
\text { NT.32 } \\
\text { NTF.11 }\end{array}$ & $\begin{array}{l}\text { struction } \\
\text { Bilious vomit and diarrhoea } \\
\text { Hiatus hernia } \\
\text { Recurrent vomiting food } \\
\text { Bilious vomit and diarrhoea }\end{array}$ & $\begin{array}{l}\text { Improved after conversion to pyloroplasty } \\
\text { Awaiting reoperation } \\
\text { Satisfactory after refashioning of stoma } \\
\text { Improved on pancreatic extract }\end{array}$ \\
\hline
\end{tabular}

Dumping was not a common complaint after operation, and in only two cases (Table V) was it a serious complication. In the remainder the unpleasant effects could usually be avoided by abstaining from certain foods, particularly sweet milk puddings and chocolate.

Diarrhoea was present in 46 patients, and was of equal frequency in patients with stimulation tests and those without. In $6(4 \%)$ it was a troublesome symptom, and the major reason for conversion of gastro-enterostomy to pyloroplasty in two cases (Table $\mathrm{V})$. The remainder suffered from intermittent loose stools amounting to two to four bowel movements a day for one or two days every six to eight weeks. This was sufficient to detract from the full benefit of operation but was regarded by the majority as a small price to pay for their freedom from ulcer distress.

Table $\mathrm{V}$ shows the reasons for classifying patients in the "poor" category. Of the 14 cases six improved after further operation and were later classified under "excellent" or "good" results; three others on medical treatment were later placed in the "good" category.

Abbreviated histories of the six patients with recurrent ulceration are shown below, including details of pre- and postoperative augmented histamine tests, insulin tests, electrical stimulation tests, barium meals, and operative findings.

The patients with recurrent ulceration were studied to see whether there had been an inadequate reduction of acid secretion after vagotomy. If a reduction in acid output of less than $65 \%$ is accepted as inadequate, there is only one case (NT.20) which possibly falls into the group described by Gillespie and Kay (1961). The other two (NT.35 and NTF.7) with inadequate depression of acid secretion were associated with incomplete nerve-section, as indicated by the insulin tests, and proved at operation in one case. In the remainder adequate reduction of acid secretion was achieved. The criteria of selection for operation described by Bruce et al. (1959) were also examined. Patients were divided into those with high and those with low secretion, an arbitrary value of $40 \mathrm{mEq} /$ hour after histamine being chosen as the discriminant value (Table VI). Only 132 histamine-test results are available, because nine of the test group and five of the control group either did not have tests or the results were invalidated. 
TABLE VI

\begin{tabular}{ll|c|c|c|c}
\hline & Test & No Test & Total & Recurrence \\
\hline Acid $>40 \mathrm{mEq} /$ hour & $\ldots$ & 23 & 18 & 41 & 2 \\
\hline Acid $\$ 40 \mathrm{mEq} /$ hour & $\cdots$ & 56 & 35 & 91 & 4 \\
\hline & & 79 & 53 & 132 & 6 \\
\hline
\end{tabular}

In one patient with a recurrent ulcer the result of the preoperative histamine test was not available, but, on the assumption that this is $>40 \mathrm{mEq} / \mathrm{hour}$, there are two patients with recurrent ulcer out of 41 with high acid secretion and 4 out of 91 with acid $\leqslant 40 \mathrm{mEq} /$ hour. Orr (1963) uses vagotomy and drainage exclusively for patients with a high basal secretion ( $>5 \mathrm{mEq} /$ hour). Only one patient with recurrent ulcer (Case NT.35) had a high basal secretion and recurrent ulceration, and this may well be attributed to incomplete vagotomy.

\section{Cases of Recurrent Ulcer}

Case T.7.-Man aged 51; dyspepsia 16 years. Pre-operative acid, basal 1.8 , post-histamine $31 \mathrm{mEq} /$ hour ; vagotomy complete on stimulation test. Recurrent ulcer symptoms within six months. Barium meal negative. No antral stasis. Histamine test showed basal 0.2 , post-histamine $8.6 \mathrm{mEq}$, acid (reduced to $27 \%$ ). Insulin test negative. At reoperation vagotomy was complete, using the stimulation test. Anastomotic ulcer found; stoma adequate. Antrectomy carried out: satisfactory result after one year.

Case T.24.-Boy aged 15; dyspepsia and recurrent haematemesis 3 years. Pre-operative acid, basal 2.3, post-histamine $26.4 \mathrm{mEq} /$ hour. Recurrent ulcer symptoms after 18 months. Barium meal showed anastomotic ulcer, confirmed by gastroscopy. No antral stasis. Post-histamine $5.8 \mathrm{mEq}$, acid (reduced to $22 \%$ ). Insulin test negative. Refused operation. Symptoms have subsided for past year.

Case TF.5.-Woman aged 58 ; dyspepsia 4 years. Pre-operative acid, basal 2.4, post-histamine $15.6 \mathrm{mEq} /$ hour. Symptoms recurred after four months. Barium meal showed persistence of duodenal ulcer and poor gastric emptying. Post-operative studies-histamine, basal 0.0 , post-histamine $4.5 \mathrm{mEq}$ (reduced to $30 \%$ ), insulin test negative. Posterior duodenal ulcer confirmed at reoperation. Stimulation test repeated with negative results. Stoma found to be extremely small. Antrectomy with Billroth I anastomosis performed, with satisfactory results at two years.

Case NT.20.-Man aged 55; dyspepsia 30 years. Pre-operative histamine test unsatisfactory and not repeated. Symptoms returned after one year. Post-operative acid, basal 3.5, post-histamine 28 $\mathrm{mEq} /$ hour. Insulin test negative. Barium meal revealed anastomotic ulcer; normal gastric emptying. Ulcer confirmed at reoperation; vagotomy was complete on stimulation test. Polya gastrectomy performed, with satisfactory results after three years.

Case NT.35.-Man aged 29 ; 5 years dyspepsia. Pre-operative acid, basal 6.1, post-histamine $45 \mathrm{mEq} /$ hour. Perforated stomal ulcer on two occasions. Polya gastrectomy performed at the time of second perforation. Acid output after first operation for perforated stomal ulcer, basal 3.5, post-histamine $23.8 \mathrm{mEq}$ (reduced to $46 \%$ ). Insulin test positive. Satisfactory result three years after gastrectomy.

Case NTF.7.-Woman aged 44 ; dyspepsia 8 years. Preoperative acid, basal 0.8 , post-histamine $23 \mathrm{mEq} /$ hour. Symptoms recurred after nine months. Post-operative acid, basal 0.2 , posthistamine $18 \mathrm{mEq}$ (reduced to $78 \%$ ). Insulin test positive. Barium meal showed anastomotic ulcer, confirmed on gastroscopy. Laparotomy confirmed stomal ulcer. Stimulation test applied and found positive. Relatively large posterior branch identified and divided. Operation completed by antrectomy and Billroth I anastomosis. Result unsatisfactory after one year owing to poor gastric emptying, recurrent vomiting, and diarrhoea.

A group of patients treated by Polya partial gastrectomy some years earlier was reviewed, using the same method of follow-up (Clark and Logie, 1962). This afforded some comparison of the results of partial gastrectomy and vagotomy and gastroenterostomy (Tables II and IV). The overall results of the two types of operation are similar, but the groups differ in the interval after operation-two to five years for vagotomy and 5 to 15 years for partial gastrectomy.

\section{Discussion}

Clark and Murray (1963) have discussed the use of the test described by Burge and Vane (1958) to ensure complete vagotomy. When the test is successfully applied the number of incomplete nerve sections is negligible. On the other hand, in the absence of the test and despite careful dissection at the lower end of the oesophagus it is estimated that the proportion of inadequate vagotomies is about $10 \%$; in a similar proportion of patients an insulin test is positive after operation. This is in close agreement with the findings of Ross and Kay (1964). The results in the two series-one where the test has been used and the other where it has been omitted-have been examined in the light of the questions posed above.

\section{Does Complete Vagotomy Confer Immunity from Recurrent Ulceration?}

This study indicates that it does not. Four patients in whom nerve section was adequate developed recurrent ulcers after operation. In one of these there was a recurrence of the original duodenal ulcer, which was attributed to stasis in the antrum due to a poorly functioning gastro-enterostomy stoma. In a second, which falls into the group described by Gillespie and Kay (1961), there was inadequate depression of acid secretion despite complete vagotomy. In the two remaining cases the preoperative acid secretion was moderate and adequate reduction followed vagotomy. In both cases the gastric emptying was satisfactory. This suggests that acidity was not solely responsible, but that other unknown factors were concerned. The augmented histamine test gives only limited information about acid secretion ; little or nothing is known about such factors as peptic activity, resistance of the mucosa to digestive properties of gastric juice, and the pattern of emptying of the stomach (Murray, 1962b).

In the untested or control group three patients developed recurrent ulceration. Two had incomplete vagotomies. In neither was the post-operative acid output satisfactorily reduced. Of 33 patients in whom post-operative insulin tests were carried out there was a positive response in three. Two of the three developed recurrent ulceration. The evidence is that if a relatively large branch of the vagus nerve escapes division at operation and if the branch contains a significant number of motor fibres there will be a reactivation of the glandular apparatus of the stomach and a return of high acid secretion (Murray, 1962a). Associated with this is a positive insulin test, and the likelihood of subsequent ulceration is considerable (Austen and Edwards, 1961).

Of the six patients with recurrent ulcers, one became symptom-free without treatment. Four responded satisfactorily to a second operation, and one failed to do so.

\section{What Effect Does Completeness of Vagotomy Have on Side-effects After Operation?}

There is no convincing evidence in this series that the incidence and degree of bilious vomiting, dumping, and diarrhoea are greater the more complete the vagotomy. In only six cases did diarrhoea present as a troublesome symptom-an incidence similar to that reported by Goligher et al. (1964) and Cox and Bond (1964). In none was there the extreme urgency amounting to incontinence described by Burge et al. (1964). Troublesome diarrhoea suffered by three patients is satisfactorily controlled with pancreatic extract.

The frequent association of diarrhoea and bilious vomiting that we have noted suggests a common aetiology, and this is 
supported by the fact that two patients with severe diarrhoea and bilious vomiting were cured by conversion of the gastroenterostomy into a pyloroplasty. Other side-effects were related to the gastro-enterostomy. In one patient bilious vomiting was caused by distortion of the stoma by an adhesion and was cured by its division. In another there was recurrent vomiting of food due to an abnormally small opening, and the condition was satisfactorily overcome by refashioning the stoma. One recurrent ulcer was associated with poor drainage of the antrum.

No doubt vagotomy, probably by altering motility in the proximal gastro-intestinal tract, predisposes to troublesome side-effects. But it is clear from this study that the drainage procedure also plays a vital part in poor results and in failures. Gastric emptying is a dynamic process (Armitage and Dean, 1963), and we believe with Tanner (1964) that much more should be known about the mechanism of emptying following gastro-enterostomy, particularly as regards the site and size of the stoma and its orientation with the circular muscle of the stomach. Given better understanding of gastric emptying, there still remains the problem of the jejunal loop. This by-passes the duodenum and must therefore reduce absorption both of iron and of calcium and impair the mixing of fat with pancreatic and biliary secretions, with consequent defective fatabsorption (Butler, 1961 ; Clark et al., 1964a). Pyloroplasty, with least disturbance of normal anatomy, would seem to offer many attractions, and we now use this procedure routinely in preference to gastro-enterostomy. But the rate and pattern of emptying of the stomach is influenced by the resistance at the pylorus and the "pumping" action of the circular muscle in the antrum (Armitage and Dean, 1963). These factors in turn are materially altered by the length of the pyloroplasty incision in the antrum, and we must have greater insight into this problem.

There is no indication in this series that the augmented histamine test can be relied upon to determine which patients will benefit from vagotomy and which will not. Patients with high secretory rates pre-operatively, whether basal or following histamine stimulation, did not appear to be more liable to recurrent ulceration than those with moderate or low acid outputs, nor was any correlation found between the pre-operative basal or histamine-stimulated secretions and the incidence and degree of side-effects following operation.

\section{Comparison of Results of Partial Gastrectomy and Vagotomy and Gastro-enterostomy}

In comparing the results caution must be exercised, however, because the partial-gastrectomy series preceded the vagotomy group, and the follow-up was over a longer period. The method of classification of results in both groups had as one of its main purposes the assessment of the incidence and degree of sideeffects. If the assessment had been based solely on simple questions, included in the standard set-for example, whether the patients were satisfied with the results of the operation or with their fitness for work and pleasure-the satisfactory results would have exceeded $90 \%$. But when a history of side-effects was elicited by direct questioning and an estimate was made of their results on health, work, and social activities, the number of satisfactory results fell to $86-88 \%$.

The unsatisfactory results were similar in number in the vagotomy and gastrectomy groups. The frequency of common symptoms due to post-operative disturbance of alimentary function does not differ greatly from that reported by Goligher et al. (1964). Vomiting, either bile or food, was commoner in the vagotomy than in the gastrectomy group. It was a feature in nine of the "poor" results of vagotomy. In at least four of these it was associated with faulty functioning of the gastroenterostomy and was cured by operation. Minor degrees of early dumping were equally common in the two groups, but in only two of the vagotomy series was it a troublesome symptom; the severer forms were commoner after gastrectomy (Clark and Logie, 1962). Diarrhoea was much more frequent after vagotomy, but the number of patients inconvenienced by it was small. Failure to gain weight after operation was much commoner after partial gastrectomy (Clark and Logie, 1962). In only one patient treated by vagotomy was it a serious feature.

The safety of any operation for duodenal ulcer is of great importance. In expert hands the mortality of gastrectomy is extremely low, but Clark and Logie (1962) estimated that the figure in these clinics engaged in a moderate amount of gastric surgery is about $2-3 \%$. Under similar circumstances in the same centre, the mortality following vagotomy and a drainage procedure is less; there was one death in 146 patients, and that was due to a pulmonary embolus.

\section{Summary}

Division of all vagal branches to the stomach is likely to lead to a decreased incidence of recurrent ulceration; nevertheless it does not confer an immunity from the complication.

There is no evidence to suggest that completeness of vagotomy increases the incidence of undesirable side-effects after operation.

Many of the poor results following vagotomy are due to defects of the drainage procedure, and a better understanding of this aspect of the problem is needed.

There is no clear support for the idea that pre-operative augmented histamine tests indicate which patients are suitable for vagotomy and which are not.

\section{REFERENCES}

Armitage, A. K., and Dean, A. C. B. (1963). Gut, 4, 174.

Austen, W. G., and Edwards, H. C. (1961). Ibid., 2, 158.

Bruce, J., Card, W. I., Marks, I. N., and Sircus, W. (1959). ₹. roy. Coll. Surg. Edinb., 4, 85.

Burge, H., Hutchison, J. S. F., Longland, C. J., McLennan, I., Miln, D. C., Ruddick, J., and Tompkin, A. M. B. (1964). Lancet, 1, 577. Butler, T. J. (1961) R. (1958). Brit. med. ₹., 1, 615

Butler, T. J. (1961). Ann, roy. Coll. Surg. Engl., 29, 300. . E. G. (1964a). Lancet. In press.

Curnow, V. J., Murray, J. G., Stephens, F. O., and Wyllie, J. H. (1964b). Gut. In press.

and Logie, N. J. (1962). F. roy. Coll. Surg. Edinb., 7, 209.

and Murray, J. G. (1963). Ibid., 8, 212.

Cox, A. G., and Bond, M. R. (1964). Brit. med. F., 1, 460.

Dragstedt, L. R., Harper, P. V., Tovee, E. B., and Woodward, E. R. (1947). Ann. Surg., 126, 687.

Gillespie, I. E., and Kay, A. W. (1961). Brit. med. F., 1, 1557.

Goligher, J. C., Pulvertaft, C. N., and Watkinson, G. (1964). Ibid., 1, Hollander.

Kay, A. W. (1946). Gastroenterology, 7, 606.

Murray J. Brit. med. $2,77$.

Murray, G. (1962a). Gastroenterology, 42, 197.

(1962b). Surgical Physiology of the Gastro-intestinal Tract, p. 70. Orr, I. M. (1963) of Surgeons of Edinburgh.

Orr, I. M. (1963). F. roy. Coll. Surg. Edinb., 8, 270. Ross, B., and Kay, A. W. (1964). Gastroenterology. In press.
Tanner, N. C. (1964). Brit. F. Surg., 51, 5. 